\title{
Alkali-Silica Reaction and High Performance Concrete
}

Chiara F. Ferraris

\section{August 1995}

Building and Fire Research Laboratory

National Institute of Standards and Technology

Gaithersburg, MD 20899

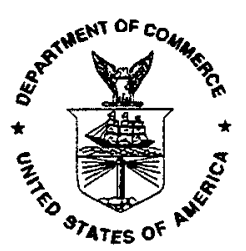

National Institute of Standards and Technology Ronald H. Brown, Secretary

Technology Administration

Mary L. Good, Under Secretary for Technology

National Institute of Standards and Technology

Arati Prabhakar, Director 


\begin{abstract}
Damage due to alkali-silica reaction (ASR) in concrete is a phenomenon that was first recognized in the U.S. since 1940 and has since been observed in many countries. Despite numerous studies published, the mechanism is not yet clearly understood. Nevertheless, the three major factors in concrete have been identified, i.e., the alkalies contained in the pore solution, reactive amorphous or poorly crystallized silica present in certain aggregates, and water.

In this study, we attempted to address the question: is high-performance concrete (HPC) susceptible to ASR? Researchers have not reached an agreement on this matter because factors other than the three major ones (pore solution alkalinity, aggregate morphology and water presence) play a significant role in the occurrence of ASR; these factors include aggregate gradation, w/c and compressive strength.

It was found that air content is the most important variable (other than the three majors factors cited above) that increase expansion of concretes affected by ASR. This study indicates that even HPC should be susceptible to ASR if reactive aggregates are used.
\end{abstract}

\title{
Keywords
}

Building Technology; Alkali-Silica reaction (ASR); High Performance Concrete (HPC); Standard Testing. 


\section{TABLE of CONTENTS}

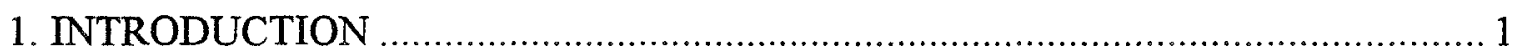

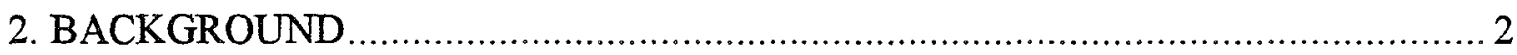

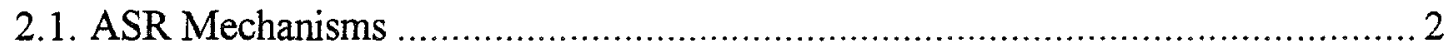

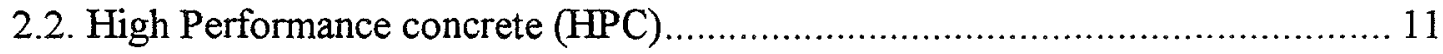

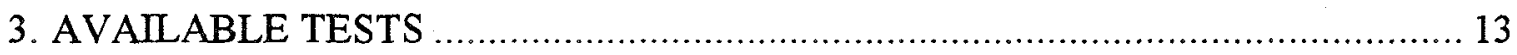

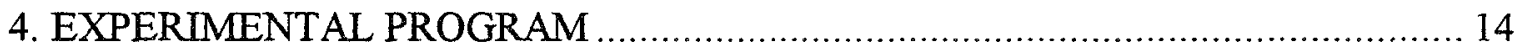

4.1. Design of High Performance Mortar (HPM) ......................................... 14

4.2. Test Configuration.................................................................... 15

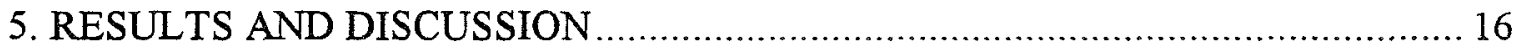

5.1. Influence of mixture design on expansion at 21 days ............................. 16

5.2. Influence of exposure conditions...................................................... 18

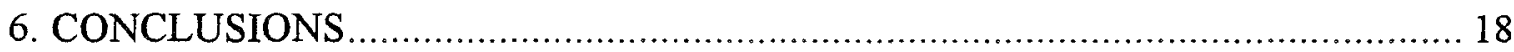

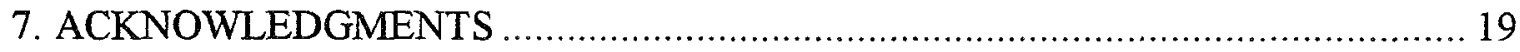

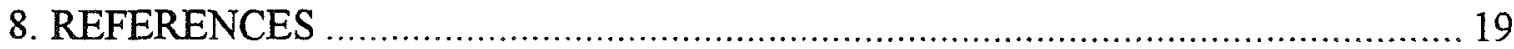




\section{LIST of FIGURES}

Figure 1: Schematic representation of the attack of alkaline solutions on silica 3

Figure 2: Pore solution composition versus time expressed from cement pastes at ages up to 1 day.[10]

Figure 3: Schema of the progression and consequence of the swelling of the ASR gel [3]. 4

Figure 4: Cracks due to ASR in concrete [3] (Hoover Dam, USA) .

Figure 5: Sketches displaying texture, morphology and compositions of the primary alkali susceptible rocks and characteristic patterns when affected by ASR [] ............ 5

Figure 6: Pessimum behavior; $w / c=0.4$ and aggregate/cement $=2.75, \ldots \ldots \ldots \ldots \ldots \ldots \ldots .6$

Figure 7: Expansion versus aggregate size[16] ................................................. 6

Figure 8: Expansion versus aggregate size; $w / c=0.41$ and aggregate/cement $=3[3] \ldots \ldots .7$

Figure 9: The influence of $\mathrm{w} / \mathrm{c}$ ratio and aggregate size on mortar expansion from

Baronio [16] suggests a relationship between $w / c$ and expansion. ................ 8

Figure 10: The influence of water/cement ratio on the expansion of concrete due to ASR shows greater expansion with increasing w/c. Aggregate/cement $=4.55[] \ldots . .8$

Figure 11: Influence of air content in hardened concrete on the relationship of expansion and age: $\mathrm{w} / \mathrm{c}=0.41 ; \mathrm{a} / \mathrm{c}=3 ;$ sodium oxide $=5 \mathrm{~kg} / \mathrm{m}^{3}[3]$

Figure 12: Alkali concentration (expressed as equivalent $\mathrm{Na}_{2} \mathrm{O}$ ) drop in pore solution of pastes as function of 1.5 year expansion of concretes A) rhyolitic tuff; B) siliceous limestone (Spratt) [] .................................................. 10

Figure 13: Schematic of the interaction of ASR and HPC. .................................. 12

Figure 14: Relation between selected parameters and expansion at 21 days. All expansions presented are the average of at least 3 bars. The compressive strength is the

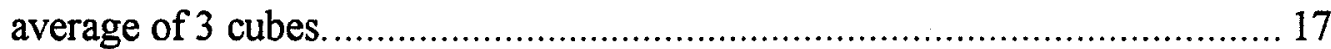

Figure 15: Expansion of HPM bars under different exposure conditions ................... 18

\section{LIST OF TABLES}

Table 1: Comparison of the alkali-silica reactivity tests ...................................... 13

Table 2: Mortar sand gradation.......................................................................... 15

Table 3: Summary of samples tested ............................................................... 16 


\section{Introduction}

Damage due to alkali-silica reaction (ASR) in concrete is a phenomenon that was first recognized in 1940 by Stanton [1,2] in North America and has since been observed in many other countries. Many studies [3,4,5] were published since Stanton's first paper, but the mechanisms of ASR are not yet clearly understood [6]. Nevertheless, the major factors have been identified, e.g., alkalies in the pore solution and reactive silica, present in certain aggregates and the presence of water. Other factors can play a significant role, such as environmental relative humidity $(\mathrm{RH})$, porosity of the concrete and presence of mineral admixtures.

High performance concrete (HPC) is usually defined as a concrete with high strength and durability. As reported by Mindess [7] from SHRP-C-205 report [8], HPC is defined by three factors:

1. Strength characteristics:

- 4-hour compressive strength $\geq 17.5 \mathrm{MPa}$ (2500 psi) or very early strength (VES)

- 24-hour compressive strength $\geq 35 \mathrm{MPa}(5,000 \mathrm{psi})$ or high early strength (HES)

- 28-day compressive strength $\geq 70 \mathrm{MPa}(10,000 \mathrm{psi})$ or very high strength (VHS)

2. durability factor greater than $80 \%$ after 300 cycles of freezing and thawing

3. water-cementitious materials ratio $\leq 0.35$.

Few studies have been reported on the relationship between the material design of high performance concrete (HPC) and ASR. It has been reported [9] that the low porosity and the presence of mineral admixtures in most HPC, will protect HPC from deterioration due to the ASR by the lack of water and by the beneficial influence of mineral admixtures. Unfortunately, we lack long term field experience on the behavior of HPC because of the young age of most HPC structures, the limited number of structures and the long time taken for the effect to manifest itself. Furthermore, we lack knowledge on the correct method to test the durability of HPC containing aggregates possibly susceptible to ASR.

In this report, after a brief literature review, we will examine existing tests for applicability to HPC. The results of some tests conducted at the National Institute of Standards and Technology (NIST) on high performance mortars (HPM) will be discussed. Recommendations for further studies and possible test methods are given. 


\section{Background}

\subsection{ASR Mechanisms}

Most researchers agree that the main reaction of ASR is the reaction between certain forms of silica present in the aggregates and the hydroxide ions $\left(\mathrm{OH}^{-}\right)$in the pore water of a concrete $[3,4]$. Very early in the hydration of cement calcium ions are incorporated in the hydration products but potassium and sodium stay in solution and eventually they are partially incorporated into calcium silicate hydrate (C-S-H) and monosulfate $\left(\mathrm{AF}_{\mathrm{m}}\right)$. Hydroxide ions from the hydration of portland cement result in a pore solution having a $\mathrm{pH}$ of at least 12.5 [10]. Soluble alkalies raise the $\mathrm{pH}$ to about 13 or higher. Also, the amount of alkalis present in the pore water is related to the amount of soluble alkalis present in the cement. The hydroxide ions will attack a silica surface. If the silica is well crystallized the vulnerable sites are only at the exterior surface of the aggregate (Figure 1a), but in the case of poorly crystallized silica, there are many vulnerable sites in the aggregate structure, leading to disintegration of the silicate network $[11,12]$ (Figure 1b). To keep a neutral charge balance, the cations $\mathrm{Na}^{+}$and $\mathrm{K}^{+}$diffuse toward the hydroxide ions to react with them and the resulting product is a gel-like material. According to Powers and Steinour [13] the migration of cations of $\mathrm{Na}^{+}$and $\mathrm{K}^{+}$is slow, therefore the migration of $\mathrm{Ca}^{2+}$ takes place. If the gel is high in calcium, then the gel is not expansive when exposed to water and, therefore, may not induce cracking in concrete. This theory rests on the assumption that calcium could be available. Diamond found that there is very little calcium in the pore solution (Figure 2). This is expected since the high $\mathrm{pH}$ causes the solubility of $\mathrm{Ca}(\mathrm{OH})_{2}$ to be depressed. Nevertheless, calcium could be dissolved from the solid phase of cement paste to produce a gel. Most researchers do not mention the distinction between "safe" and "swelling" gel but there are acknowledgments that there are more than one composition of gel produced by ASR [12]. 

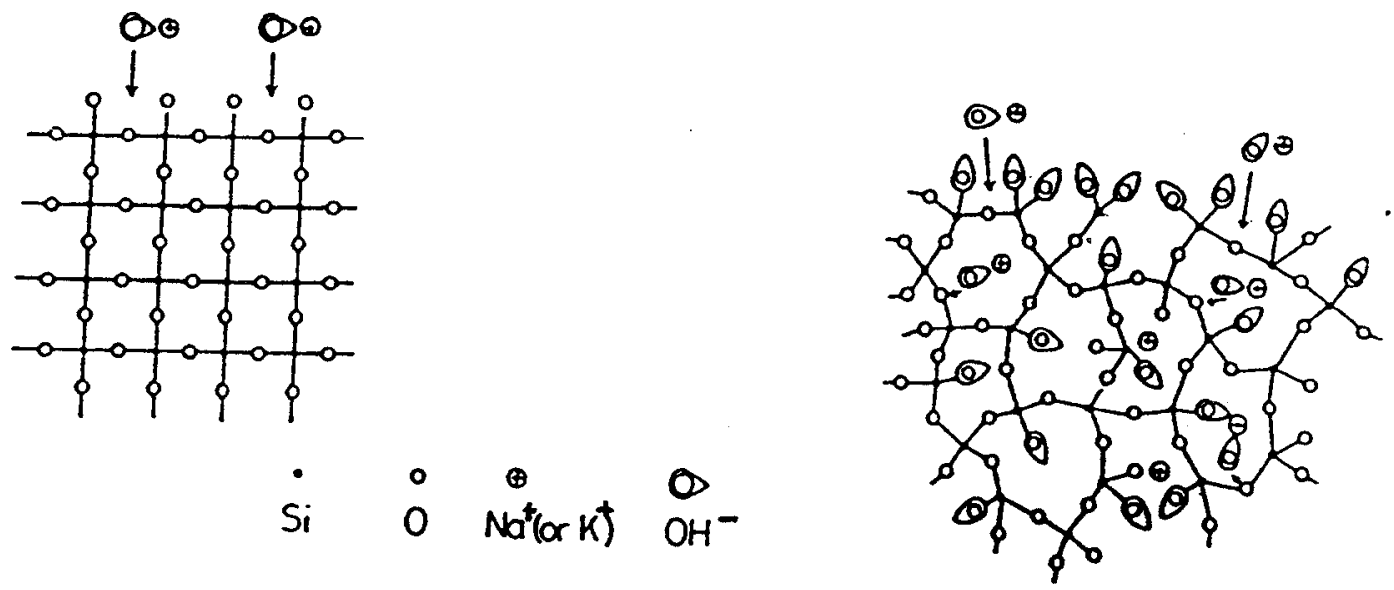

Figure 1: Schematic representation of the attack of alkaline solutions on silica a) Well crystallized silica b) Poorly crystallized silica.[11]

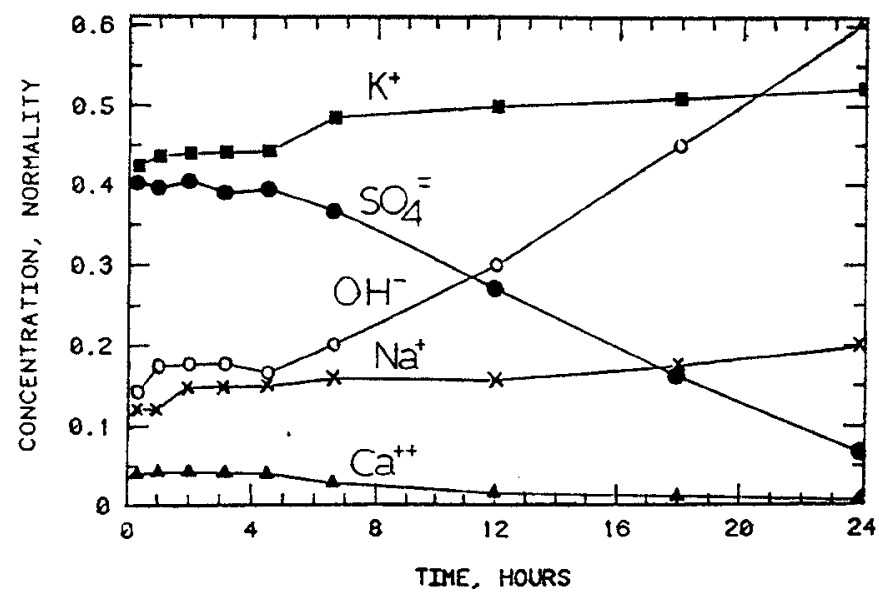

Figure 2: Pore solution composition versùs time expressed from cement pastes at ages up to 1 day.[10] 
The formation of the gel per se is not deleterious. The deterioration of the concrete structure is due to the water absorption by the gel and its expansion. It is reported $[11,14]$ that the $\mathrm{RH}$ must be higher than $80 \%$ for the gel to swell although it can be formed at lower relative humidities. According to Hobbs [3] the progression of the swelling of ASR gel follows the general patterns shown in Figure 3. As the tensile strength of the system is exceeded, cracks will form and propagate. As there is not a preferential direction for cracks to propagate and also the sites of crack initiation are randomly distributed in the specimen, map cracking will be characteristic of ASR deterioration (Figure 4). The sites of the cracks are determined by the location of the reacting silica on the aggregates and the availability of $\mathrm{OH}^{-}$in the vicinity.
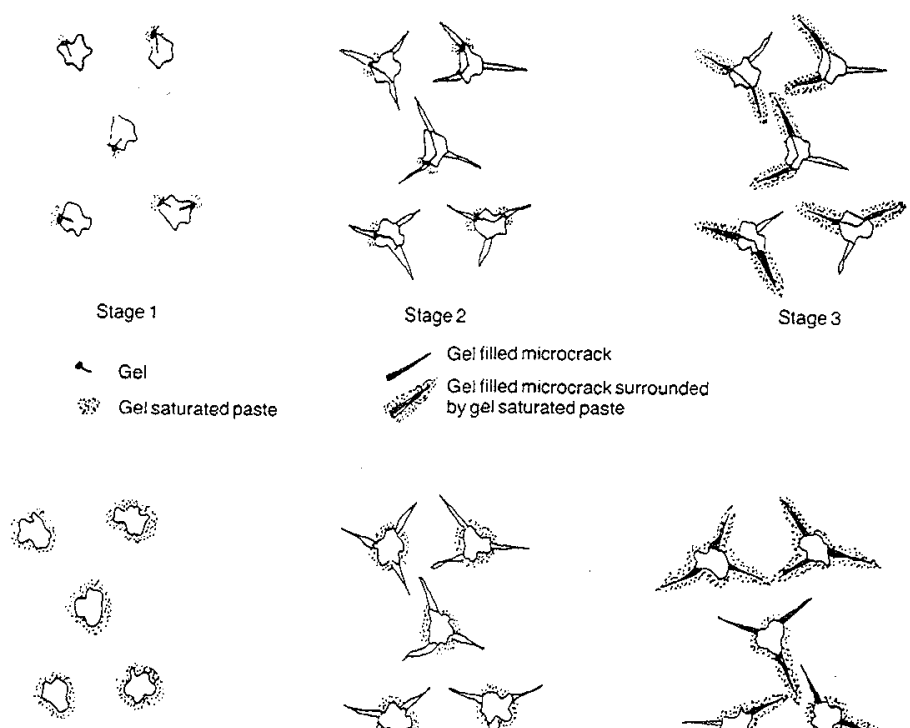

$$
\begin{aligned}
& \text { Get filled microcrack } \\
& \text { Gel filled microcrack surrounded } \\
& \text { by gel saturated paste }
\end{aligned}
$$
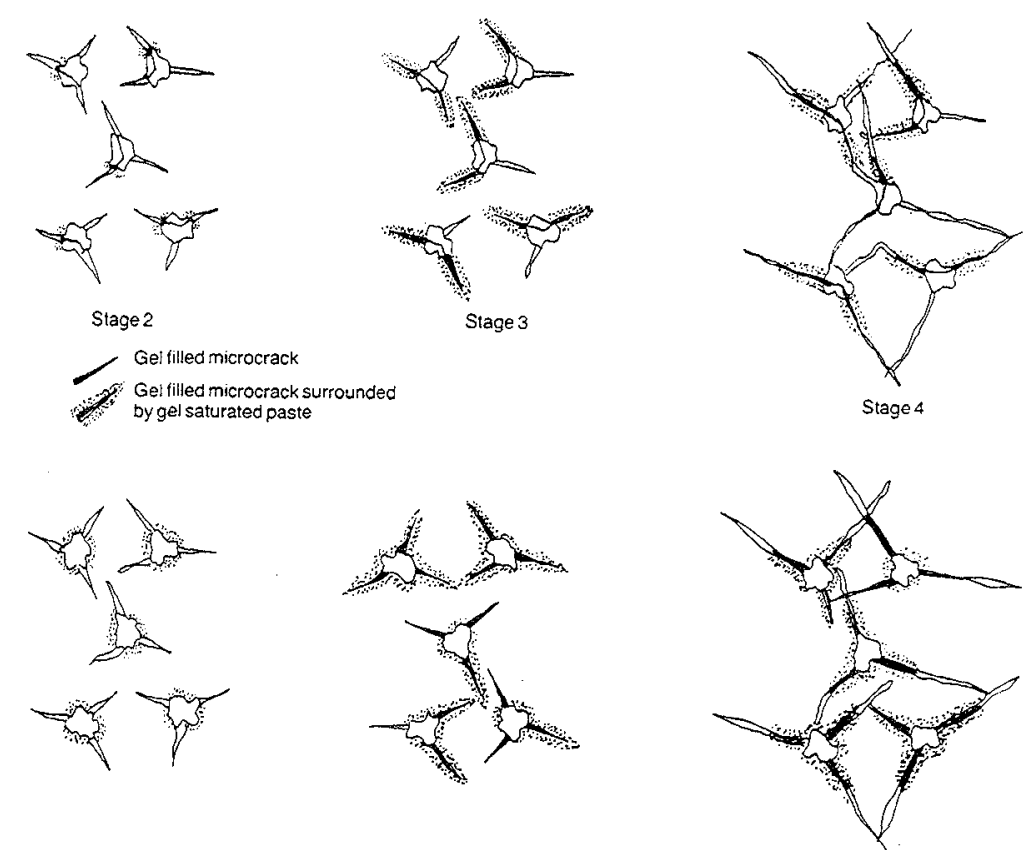

Figure 3: Schema of the progression and consequence of the swelling of the ASR gel [3].

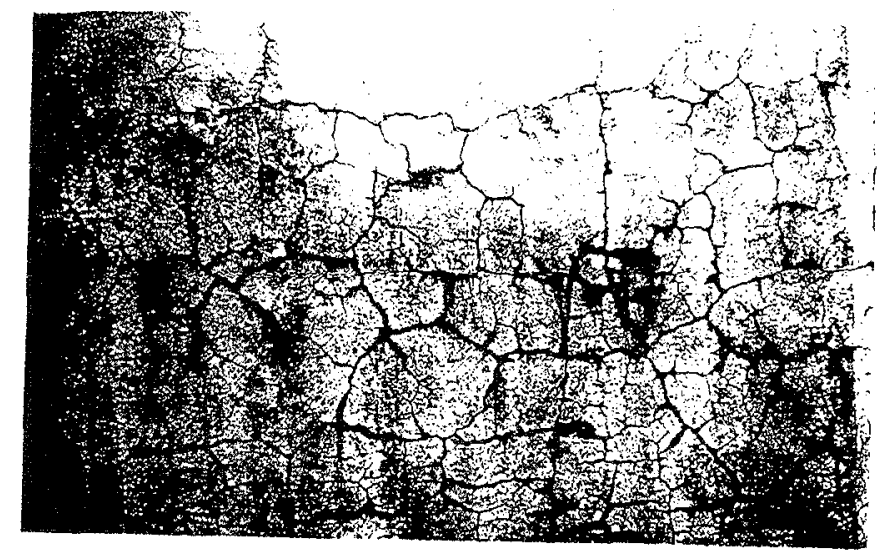

Figure 4: Cracks due to ASR in concrete [3] (Hoover Dam, USA) 
Type of reactive aggregates include [3]:

- non-crystalline or imperfectly crystalline silica, such as crystobalite, opaline, chert, flint

- strained quartz or microcrystalline quartz (often found in gneiss) shist, quartzite

- glassy to cryptocrystalline matrix of igneous rocks, such as pumice.

Figure 5 shows the various aggregates and their reaction patterns regarding ASR. A factor that is reported of importance to the deleterious activity of the aggregates is the gradation or size distribution.
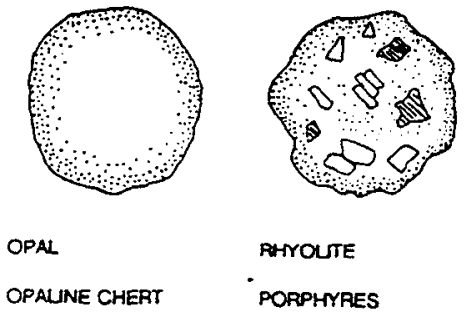

VOLCANIC GLASS

INOUSTALAL GLASS

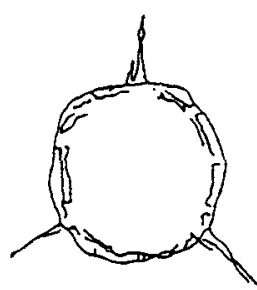

ENTIRE PAATICLE BULLDUP RESERVOIR FOR SWEUUNG GEL BEFORE BURSTING REACTION RIM OFTEN PRESENT

$$
\begin{aligned}
& \text { PHYOUTE } \\
& \text { PORPHYRES }
\end{aligned}
$$

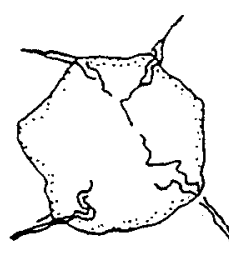

INTERNAL CRACKING WHERE CLASTIC GPANS PROMDE STIFFNESS ANO STRENGTH DURING GEL FORMATION.

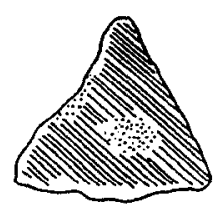

\section{DENSE FUNT \\ CHEAT}

DENSE, MICROCRYSTALUNE SHUCEOUS ROCKS

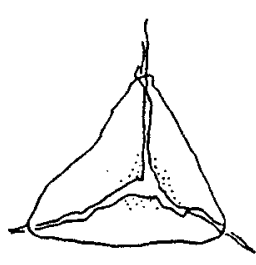
SOME RIM REACTION MAY BE VSIBLE

CONFINED INTERNAL POROUS, OPALNE REGIONS SEATS OF SWELUNG GEL FOAMATION. CAUSING

FAUSING SURROUNDING AOCK

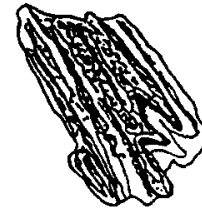

SCHST

PHYUTE

FOUATED GNEISS
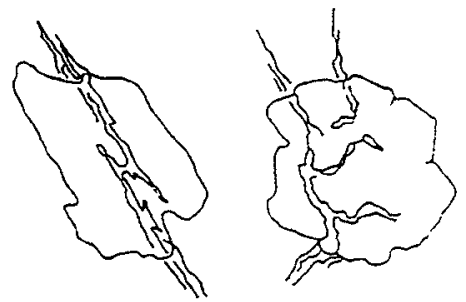
SUBSTANCE
CAACKING FOLLOWS CAACXING WEAK INTERGPANULAR ACCUMULATES PATCHES WTH FROM REGIONS SWELUNG GEL - WTH THOROUGHLY $\begin{array}{ll}\text { FORMATION } & \text { WITH THOROUGHLY } \\ & \text { DISTORTED OUARTZ }\end{array}$

Figure 5: Sketches displaying texture, morphology and compositions of the primary alkali susceptible rocks and characteristic patterns when affected by ASR [14] 
The mix design should be considered, because the aggregate content and size, the water/cement ratio and air content affect the reaction. For instance, Hobbs $[3,15]$ reports that there is a pessimum amount of aggregate that will result in a higher expansion (Figure 6). Also, Hobbs [3] and Baronio's [16] results show that the greatest expansion occurs with the finest gradation used (Figure 7 and Figure 8). Nevertheless, at very small sizes, in the order of microns, a pozzolanic effect could be expected to reduce the amount of expansion (as discussed later in this report).

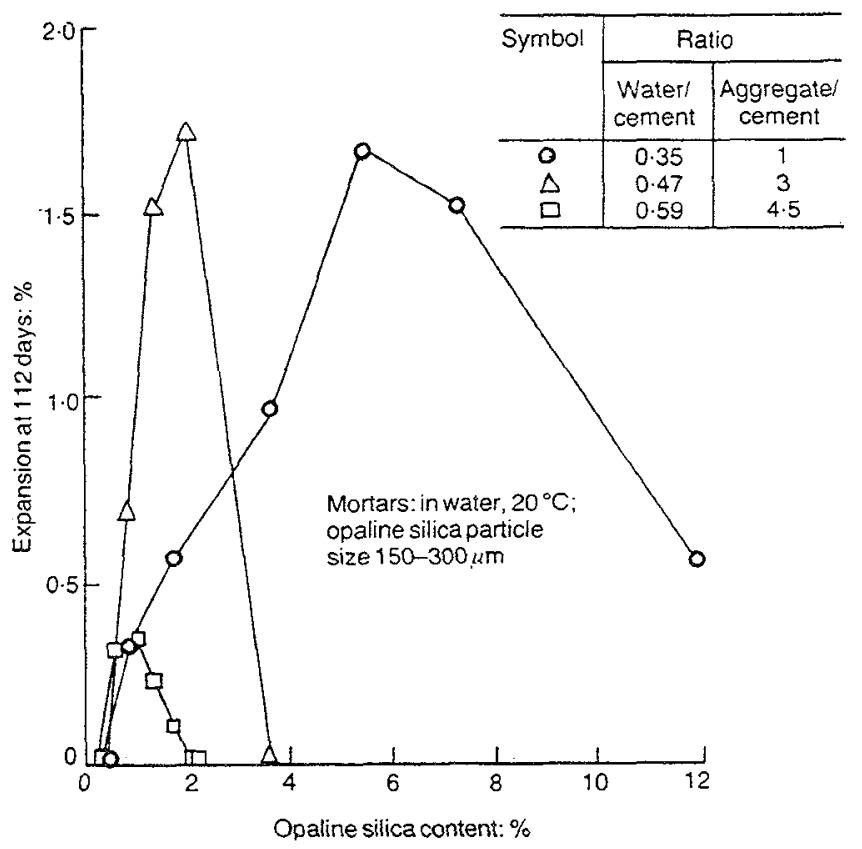

Figure 6: Pessimum behavior; $w / c=0.4$ and aggregate $/ \mathrm{cement}=2.75$, alkali content $=6 \mathrm{~kg} / \mathrm{m}^{3}[3]$.

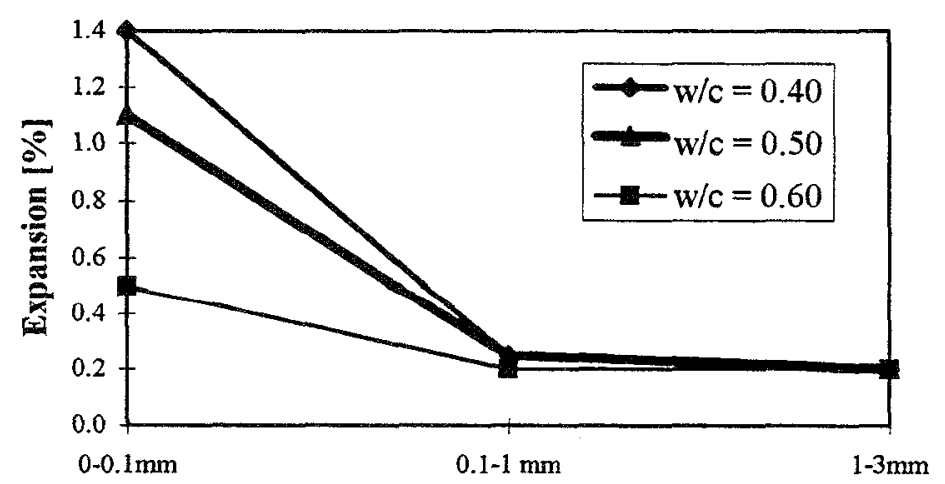

Sand sizes

Figure 7: Expansion versus aggregate size[16]. 


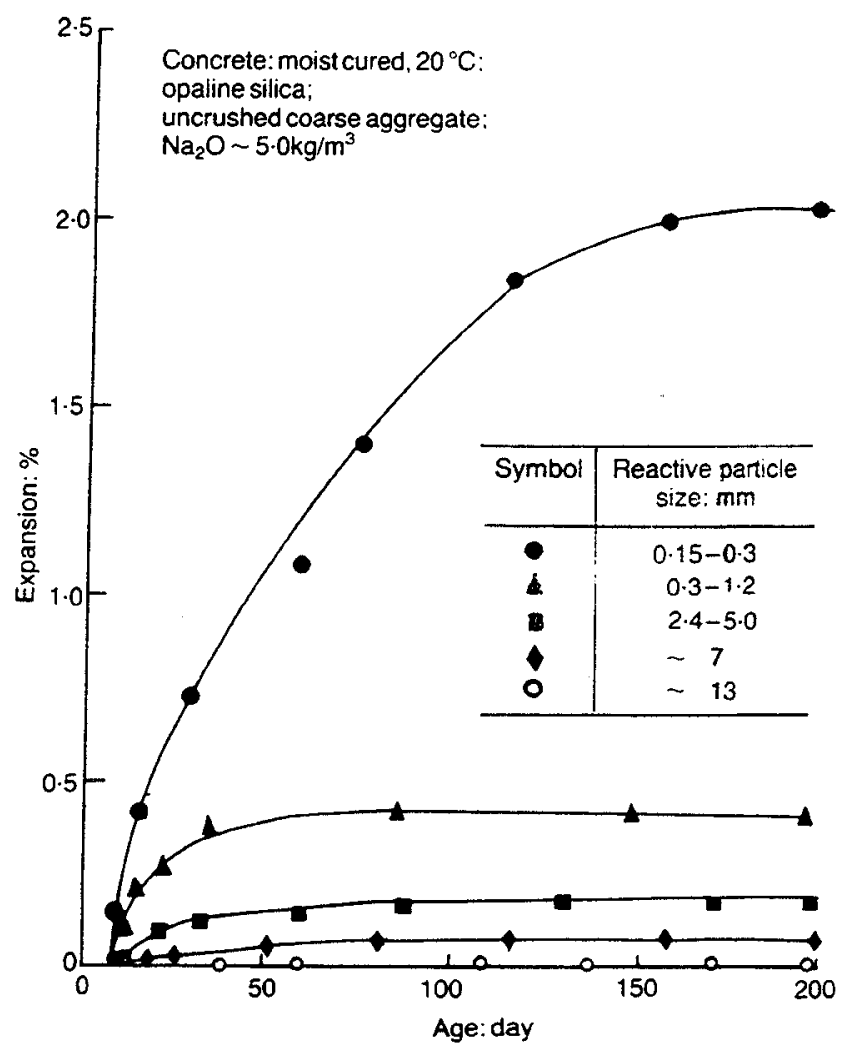

Figure 8: Expansion versus aggregate size; $w / c=0.41$ and aggregate/cement $=3[3]$

As mentioned earlier, other factors influencing the expansion due to the swelling of the reaction gel include the water/cement ratio $(w / c)$ and the air content in fresh concrete. The influence of the water/cement ratio on expansion is not clear-cut; higher w/c ratio leads to either higher or lower expansion depending on other factors such as age and aggregate size. Figure 9 and Figure 10 show that the higher $w / c$ ratio generally results in a higher expansion, but in one case (gradation $\mathrm{B}$ : $\mathrm{w} / \mathrm{c}=0.6$ lower than $\mathrm{w} / \mathrm{c}=0.5$ ), the reverse was found. 


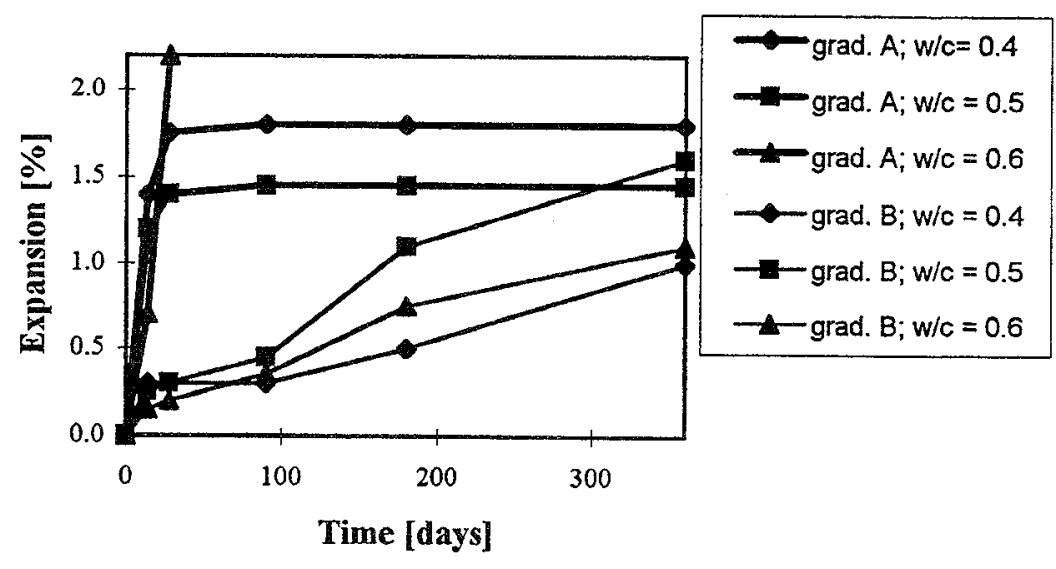

Figure 9: The influence of $w / c$ ratio and aggregate size on mortar expansion from Baronio [16] suggests a relationship between $\mathrm{w} / \mathrm{c}$ and expansion. Grad. A $=0-0.1 \mathrm{~mm}$; Grad. B $=0.1-1 \mathrm{~mm}$. The original graph included another gradation $\mathrm{C}$ with size 1-3 $\mathrm{mm}$ that showed no influence of the $w / c$.

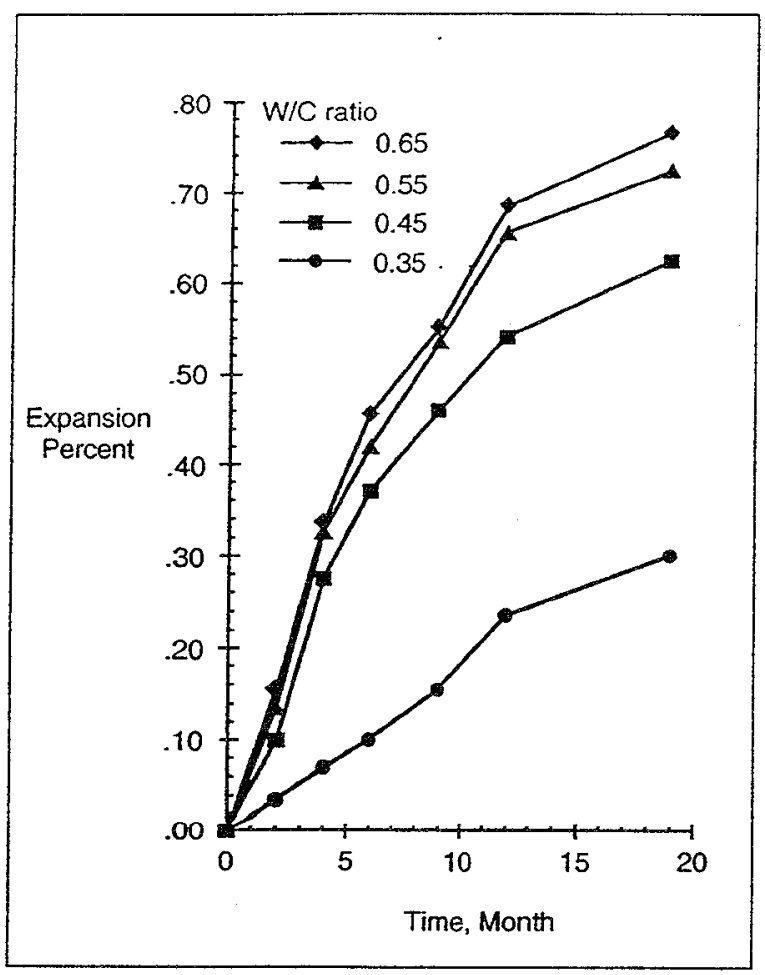

Figure 10: The influence of water/cement ratio on the expansion of concrete due to ASR shows greater expansion with increasing $w / c$. Aggregate/cement $=4.55$ [17] 


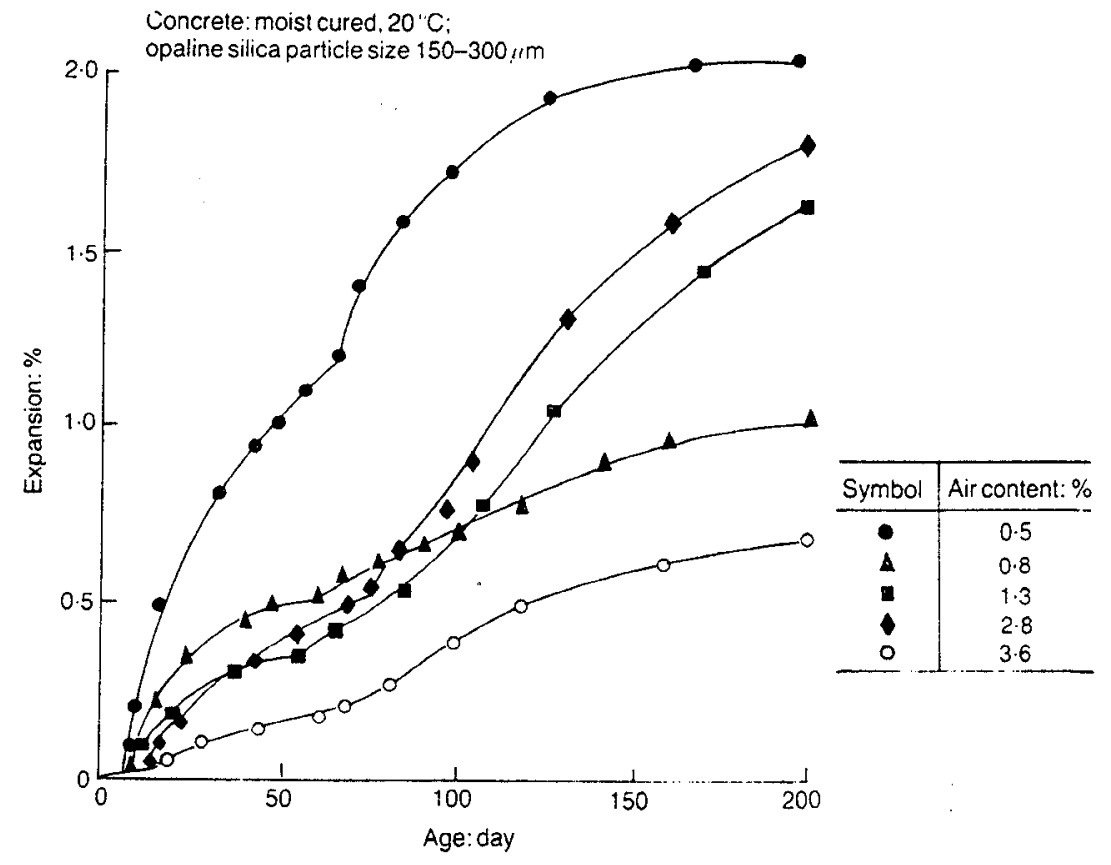

Figure 11: Influence of air content in hardened concrete on the relationship of expansion and age: $\mathrm{w} / \mathrm{c}=0.41 ; \mathrm{a} / \mathrm{c}=3 ;$ sodium oxide $=5 \mathrm{~kg} / \mathrm{m}^{3}[3]$.

The air content influence is illustrated in Figure 11. It indicates that the higher air content results in lower expansion. This could be explained by the gel expanding into the available capillary pores or voids, without stressing the structure of the cement matrix.

The addition of pozzolanic fillers, such as fly ash [18], silica fume or other mineral admixtures has been shown to reduce the expansion of concrete affected by ASR [18]. The mechanisms are not well understood, but it is agreed that the silica contained in the mineral admixtures reacts faster $[4,19]$ with the $\mathrm{OH}^{-}$than the silica contained in the aggregates. Therefore, the alkalis are rapidly consumed and the level of $\mathrm{OH}^{-}$reduced to a level at which aggregates react very slowly or not at all The beneficial response of some samples containing mineral admixtures is demonstrated in Figure 12. However, not all mineral admixtures are beneficial, e.g., PFA-C or CSF-B in Figure 12. This inconsistency is not clearly understood at the moment, but it has been suggested that the mineral admixtures that do not counteract ASR are not removing alkalis from the solution. Also, some mineral admixtures contain deleterious amounts of alkalies. ASTM has a limit on alkali content of a mineral admixture (such as fly ash) if it is to be used with ASRsusceptible aggregates. 

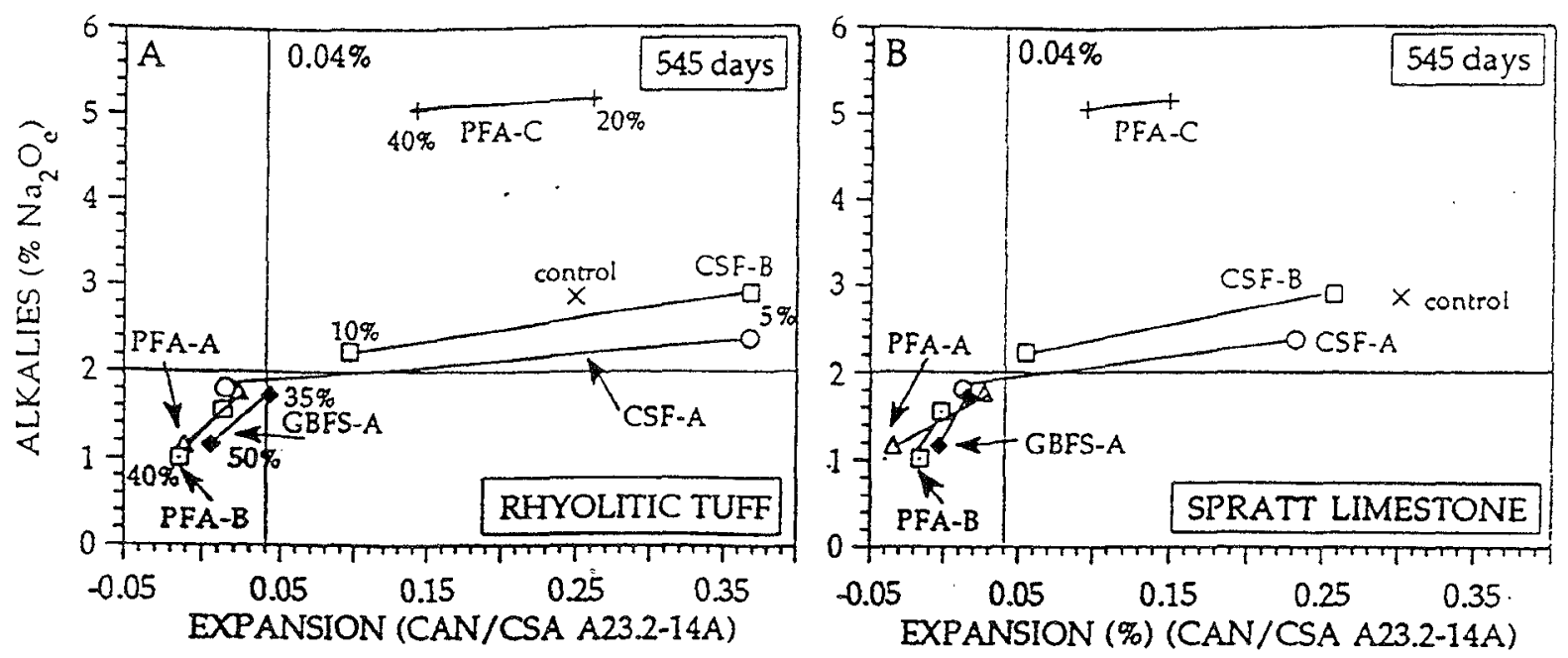

Figure 12: Alkali concentration (expressed as equivalent $\mathrm{Na}_{2} \mathrm{O}$ ) drop in pore solution of pastes as function of 1.5 year expansion of concretes A) rhyolitic tuff; B) siliceous limestone (Spratt) [20]

From this brief overview of the literature on the mechanisms, the following summarizes present knowledge on ASR:

- ASR is a reaction between the $\mathrm{OH}^{-}$in the pore solution with amorphous or poorly crystallized silica in the aggregates.

- The reaction product imbibes water and expands.

- The presence of water or RH higher than $80 \%$ is necessary for the gel formed to expand and induce concrete cracking.

- Some siliceous mineral admixtures deplete the alkalis from the pore solution, lowering the $\mathrm{pH}$, therefore decreasing the likelihood of ASR.

- The aggregate type and size distribution play a significant role in the expansion measured in concretes

- Other factors influencing the cracking due to ASR include air entrainment and possibly $\mathrm{w} / \mathrm{c}$. 


\subsection{High Performance concrete (HPC)}

High performance concrete (HPC) is usually define as a concrete with high strength and durability. As reported by Mindess [21] from SHRP-C-205 report [22], HPC is defined by three factors:

- Strength characteristics:

- 4-hour compressive strength $\geq 17.5 \mathrm{MPa}$ (2500 psi) or very early strength (VES)

- 24-hour compressive strength $\geq 35 \mathrm{MPa}$ (5000 psi) or high early strength (HES)

- 28-day compressive strength $\geq 70 \mathrm{MPa}(10,000 \mathrm{psi})$ or very high strength (VHS)

- durability factor greater than $80 \%$ after 300 cycles of freezing and thawing

- water-cementitious materials ratio $\leq 0.35$.

As stated in the introduction we lack knowledge of the behavior of HPC in regard to ASR. There are no long-term performance data regarding ASR in HPC. Conflicting viewpoints exist as to whether ASR gel will form in HPC and if it does form, whether the higher tensile strength will be sufficient to prevent the concrete from cracking.

According to some researchers $[9,23]$, the use of silica fume will prevent the reaction from occurring as noted in Section 2.1. Shah [9] states: "for the high-strength concrete the effect of self-desiccation may reduce the moisture content to a level where no alkali-aggregate reaction can take place". Criaud et al.[23] state that the lower porosity should prevent the diffusion of $\mathrm{OH}^{-}$to the reaction sites. They imply that neither hydroxide ions nor water can migrate to the reaction sites. However, it can be argued that, at low w/c and low air content, the decreased porosities should result in a lack of space (capillary pores and cracks) for the reaction gel to expand into. Also, it should be realized that water is present at the beginning for the hydration of cement and some reaction could occur before all the water is consumed.

The significant parameters are summarized in Figure 13. The shaded areas correspond to parameters affected by the HPC design and processing. 


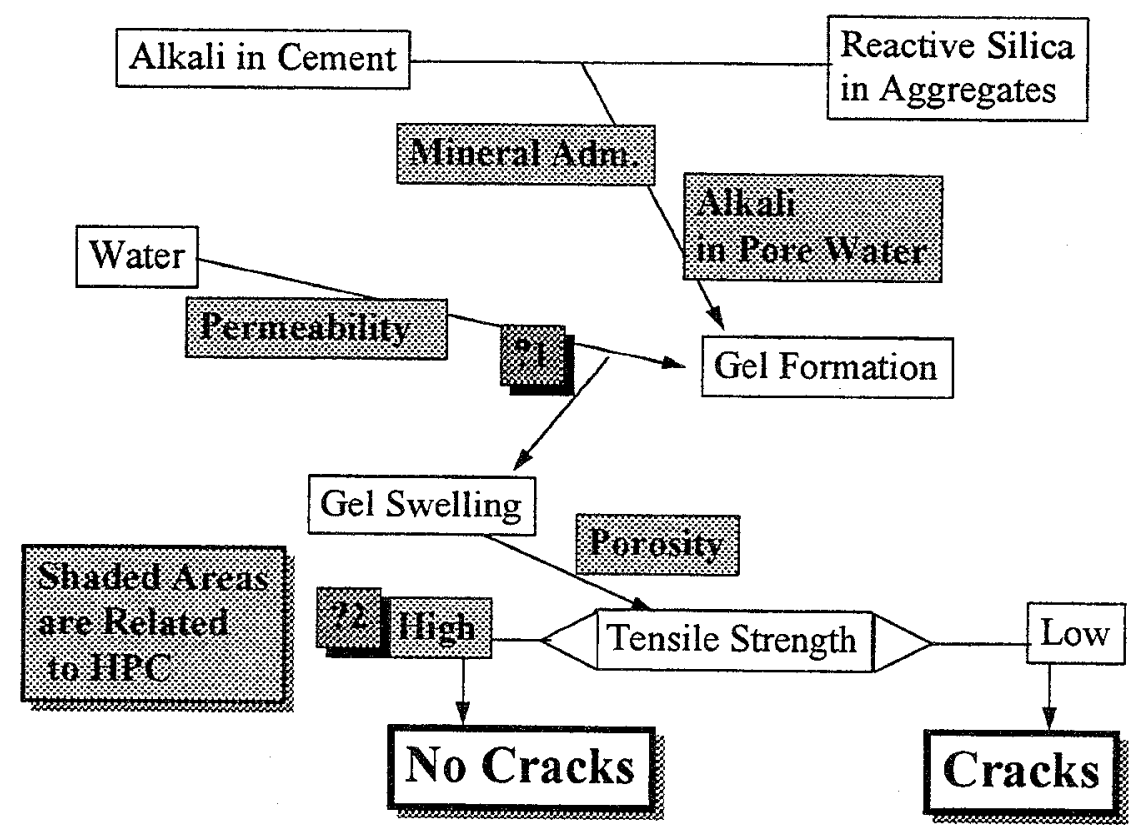

Figure 13: Schematic of the interaction of ASR and HPC.

According to our flow chart of the response of HPC to ASR (Figure 13), two areas (marked 1 and 2 in Figure 13) need to be investigated to determine if HPC is susceptible to ASR. The two issues are:

- "?1": Permeability:

If the permeability of HPC is such that water is not reaching the gel, then no swelling and no cracks will occur.

- "?2": Tensile strength:

If the tensile strength of HPC is higher than the stress generated by the swelling of the gel, then no cracks will occur.

We have planned an experimental study to address both issues. In this report, a response to only the first issue ("? 1"(Permeability)) is presented. Tests are underway for responding to the second issue ("?2" (Tensile strength)) but sufficient data are not available yet. 


\section{Available tests}

The first goal of this report is to determine which one of the available tests is applicable to detect ASR in HPC. All tests could be classified in two categories:

- Tests on aggregates alone

- Tests on mortar or concrete samples containing aggregates

Only the second category of tests is potentially applicable to HPC because they address the combination of cement and aggregates used. Therefore, in this report we will examine closely the tests in the second category.

There are three tests that fall in this category: ASTM C1260 [24] , ASTM C227 [25] and a French microbar method [26]. Other tests found in the literature are modifications of the above tests. Table 1 gives the major characteristics and differences of these three tests.

Table 1: Comparison of the alkali-silica reactivity tests

\begin{tabular}{|c|c|c|c|}
\hline Test 1 appellation & ASTM C1260 & ASTMC227 & Microbars \\
\hline Sample design & $\begin{array}{l}\text { mortar bars; } \\
\text { w/c }=0.50 \\
\text { aggregates: fixed gradation } \\
\text { sand/cement }=2.25\end{array}$ & $\begin{array}{l}\text { mortar or concrete bars } \\
\text { w/c not specified } \\
\text { aggregates: fixed gradation } \\
\text { sand/cement }=2.25\end{array}$ & $\begin{array}{l}\text { mortar bars } \\
\text { w/c }=0.3 \\
\text { sand: fixed gradation } \\
\text { s/c suggested }\end{array}$ \\
\hline $\begin{array}{l}\text { Measurement } \\
\text { conditions }\end{array}$ & $\begin{array}{l}\text { In a } 1 \mathrm{~N} \mathrm{NaOH} \text { solution at } \\
80^{\circ} \mathrm{C}\end{array}$ & at $100 \% \mathrm{RH}$ and $38^{\circ} \mathrm{C}$ & $\begin{array}{l}\text { at } 150^{\circ} \mathrm{C} \text { in } 10 \% \mathrm{KOH} \\
\text { solution }\end{array}$ \\
\hline $\begin{array}{l}\text { Criteria of } \\
\text { expansion }\end{array}$ & $\begin{array}{l}\text { Deleterious if } \\
\text { expansion }>0.2 \% \text { at } 14 \\
\text { days }\end{array}$ & $\begin{array}{l}\text { Deleterious if } \\
\text { - expansion }>0.1 \% \text { at } 12 \\
\text { months } \\
\text { expansion }>0.05 \% \text { at } 6 \\
\text { months }\end{array}$ & $\begin{array}{l}\text { Deleterious if } \\
\text { expansion }>0.11 \% \text { at } \\
3 \text { days }\end{array}$ \\
\hline
\end{tabular}

A major difference between these tests is the duration of the measurements, i.e., from 3 days to 12 months. Of course, the rapid tests are more appealing but the following variables could not be tested as specified, because they are specified by the test method:

- The alkali content of the cement: the alkalis supplied by the solution should be more than enough to cause ASR, therefore the alkali content of cement is irrelevant

- The mixture design of the sample.

- The aggregate grading.

In these tests, the samples cannot be classified as high performance materials because the specified mixture designs are typical of conventional-based materials. This is because the tests were designed to determine whether an aggregate is suitable for use in concrete, i.e., whether it is subjected to ASR. They were not intended to test mixture designs. 
Another test of possible relevance is ASTM C 441 [27], used to determine the effectiveness of mineral admixtures in preventing ASR is. However, it is not suitable because the sand gradation is fixed, the aggregate is a highly-reactive Pyrex glass, and the $\mathrm{w} / \mathrm{c}$ ratio is determined from the flow measured by a flow table.

Therefore, the only test that could be easily modified to make it applicable to HPC is ASTM C227. One modification is required, i.e., the fixed sand gradation needs replacement by one that will increase flow (at low $\mathrm{w} / \mathrm{c}$ ) and minimize permeability. The ASTM C1260 test might be used to test some parameters such as porosity or mixture design if mineral admixtures were not used, but the sand gradation would have to be modified to reflect a HPM mix.

\section{Experimental program}

\subsection{Design of High Performance Mortar (HPM)}

We defined a high performance mortar, as a mortar with some of the characteristics of HPC, i.e., low w/c, low porosity, high strength. In this report we did not consider the use of mineral admixtures. Therefore, to design a high performance mortar, we imposed the following conditions:

- low w/c, about 0.30

- low sand/cement ratio $(\mathrm{s} / \mathrm{c})$ of 1.4

- low air content $(<2-3 \%)$

To design our HPM, we proportioned four graded sands from the same manufacturer and with the same composition. The gradation was selected to obtain the highest flow and the lowest air content. Carino et al. [28] had already found a s/c ratio that gave a high compressive strength. We modified the mixture design slightly by using a sand gradation that followed the Fuller curve [29]. This gradation should give the highest compaction and the best flow. The w/c ratio was adjusted to obtain a flowable mixture as measured by a flow table (ASTM C 230 [30]).

The sand was a fused silica (Tecosil") and was available in a variety of particle sizes. This selection gave us flexibility to determine the best gradation without the tedious work of grinding the coarse aggregate to a specified size distribution as prescribed by ASTM C1260. Table 2 gives the sand gradation used.

\footnotetext{
${ }^{*}$ Tecosil is fused silica from C-E Minerals, 901 East Eighth avenue, King of Prussia, PA 19406. The name of the manufacturer is identified in this report to adequately describe the experimental procedure. Such an identification does not imply recommendation or endorsement by the National Institute of Standards and Technology, nor does it imply that the material identified is necessarily the best available for the purpose.
} 
Table 2: Mortar sand gradation

\begin{tabular}{|c|cc|c|}
\hline \multirow{3}{*}{$\begin{array}{c}\text { Mortar } \\
\text { Designation }\end{array}$} & \multicolumn{3}{|c|}{ Sand } \\
\cline { 2 - 3 } & Size range & \multirow{2}{*}{ Mass } \\
& Sieve size & Dimension & \\
& ASTM E11 & {$[\mu \mathrm{m}]$} & {$[\%]$} \\
\hline HPM & $50-100$ & $300-150$ & 25 \\
& $20-50$ & $850-300$ & 25 \\
& $10-20$ & $2000-850$ & 35 \\
& $4-10$ & $4750-2000$ & 15 \\
\hline ASTM C1260 & $50-100$ & $300-150$ & 5 \\
& $20-50$ & $850-300$ & 30 \\
& $10-20$ & $2000-850$ & 30 \\
& $4-10$ & $4750-2000$ & 35 \\
\hline
\end{tabular}

The mortar w/c ratio varied between 0.29 to 0.47 . S/C was either 1.411 [ 28] or 2.25 as described in ASTM C1260. High range water reducing agent (HRWR) was used for all HPM mixes.

\subsection{Test Configuration}

To measure expansion due to ASR, bars $(25 \mathrm{~mm} \times 25 \mathrm{~mm} \times 279 \mathrm{~mm}$ (1 in. $\mathrm{x} 1 \mathrm{in}$. $\mathrm{xll}$ in.)) were prepared using the above-mentioned mixture design. The cement used had a high alkali content (about $1.2 \% \mathrm{Na}_{2} \mathrm{O}$ equivalent). As the high alkali content of the cement should result in high alkali concentration in the pore solution, this cement should promote ASR with reactive siliceous aggregates.

To test the influence of parameters such as $w / c, s / c$, air content, sand gradation and duration of curing, the conditions of testing were as described in ASTM C1260, i.e., $80^{\circ} \mathrm{C}$ in a solution of $1 \mathrm{~N} \mathrm{NaOH}$. These test conditions were intended to promote a reaction faster than in normal field situation. Therefore, to test if HPC will be subject to ASR, we exposed some bars to a less severe environment, i.e., $100 \% \mathrm{RH}$ and $20^{\circ} \mathrm{C}$. This test has the advantage of more closely simulating field conditions but it could lead to a relatively slow reaction rate, increasing the time to obtain data. Most data were obtained using the first set of conditions because we wanted a rapid test to determine the influence of some of the mixture design parameters. Only one set was tested using the second conditions. 


\section{Results and discussion}

\subsection{Influence of mixture design on expansion at 21 days}

Table 3 gives the mixture designs and other experimental variables that were selected for this set of tests.

Table 3: Summary of samples tested

\begin{tabular}{|c|c|c|c|c|c|}
\hline \multirow[b]{2}{*}{ sample \# } & \multicolumn{3}{|c|}{ Mortar composition } & \multirow[b]{2}{*}{$\begin{array}{c}\text { Curing Time } \\
\text { [days] }\end{array}$} & \multirow[b]{2}{*}{$\begin{array}{c}\text { air content } \\
{[\%]}\end{array}$} \\
\hline & $\begin{array}{l}w / c \\
\text { (a) }\end{array}$ & $\begin{array}{l}\mathrm{s} / \mathrm{c} \\
\text { (b) }\end{array}$ & $\begin{array}{l}\text { Sand gradation } \\
\text { (c) }\end{array}$ & & \\
\hline ASR2-2 & 0.295 & 1.411 & HPM & $\overline{1,14}$ & 5.9 \\
\hline ASR2-25 & 0.30 & 1.411 & HPM & 1 & 13.7 \\
\hline ASR-142 & 0.32 & 1.411 & HPM & 1 & 10.7 \\
\hline ASR-164 & 0.32 & 1.411 & HPM & $1,7,14,28$ & 7.6 \\
\hline ASR2-20 & 0.40 & 1.411 & HPM & 1 & 12.4 \\
\hline ASR2-30 & 0.50 & 1.411 & HPM & 1 & 11.0 \\
\hline ASR-143 & 0.47 & 2.25 & ASTM C1260 & 1 & 8.8 \\
\hline ASR2-3 & 0.47 & 2.25 & ASTM C1260 & 1,14 & 8.9 \\
\hline ASR-166 & 0.47 & 2.25 & ASTM C1260 & 1,13 & 7.3 \\
\hline $\begin{array}{l}\text { Notes: } \\
\text { a) } w / c= \\
\text { b) } s / c=s \\
\text { c) The se }\end{array}$ & Heed a & tio & & & \\
\hline
\end{tabular}

The relationships between the w/c, s/c, curing time, compressive strength, air content and the expansion at 21 days are presented in Figure 14. From the data in Figure 14 , it can be concluded that the main variable was air content, followed by curing time. No larger expansion occurred with longer curing time. Expansion did not seem to be affected by the following parameters: $w / c, s / c$ and sand gradation. But it should be kept in mind that air content is affected by those parameters ( $w / c, s / c$ and sand gradation). Therefore, it is difficult to distinguish between the various variables tested. The compressive strength, contrary to what was expected, does not appear to affect the expansion at 21 days significantly. A trend could be seen toward higher expansion with longer curing. This might be explained by the fact that expansion at 21 days means 21 days in $\mathrm{NaOH}$, but the specimens are older. They were exposed to water during the curing period. Therefore, the reaction could have started immediately after casting and the exposure to $\mathrm{NaOH}$ and higher temperature would only have accelerated it. 

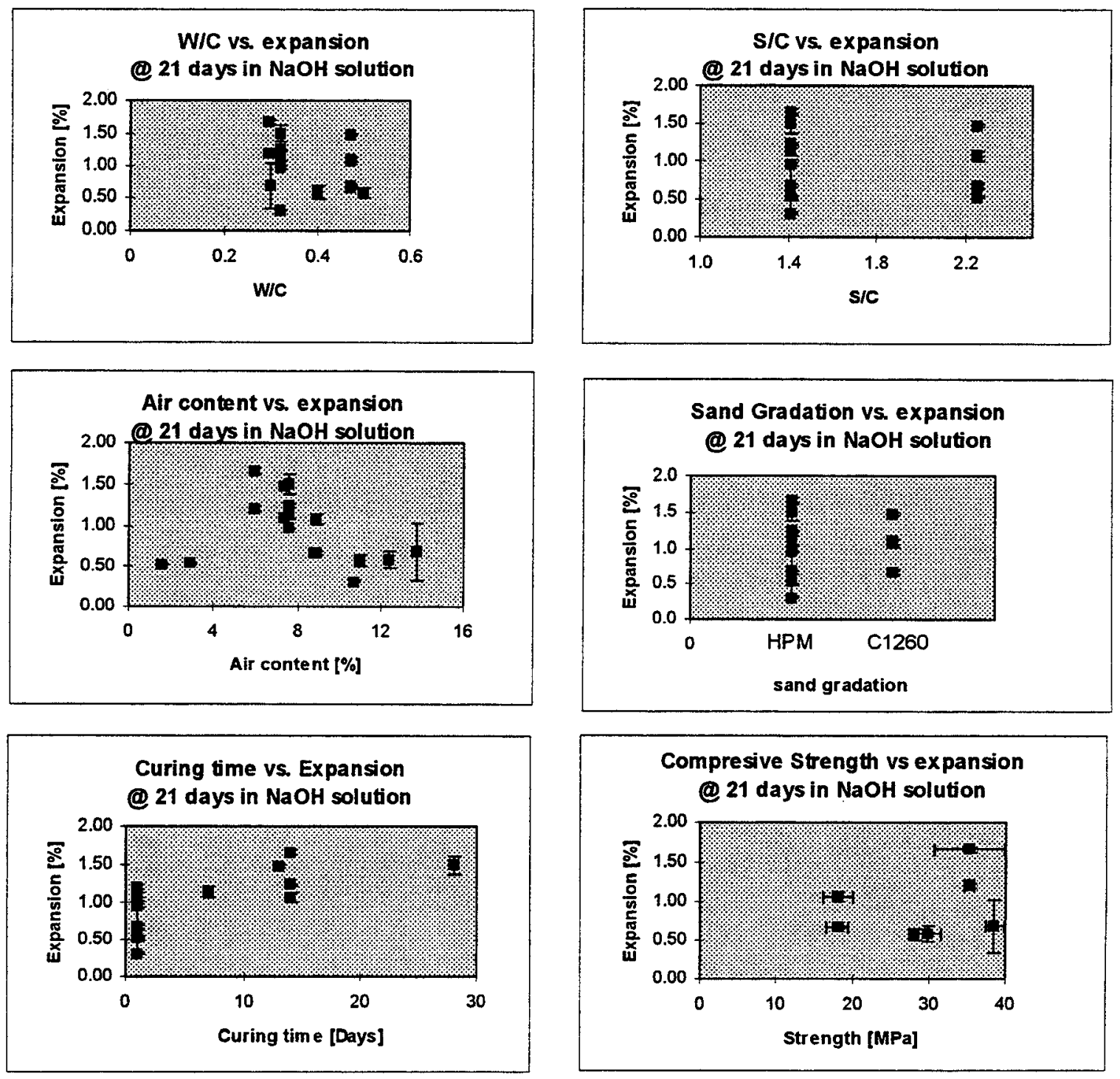

Figure 14: Relation between selected parameters and expansion at 21 days. All expansions presented are the average of at least 3 bars. The compressive strength is the average of 3 cubes. 


\subsection{Influence of exposure conditions}

As stated earlier, two types of exposure were used, ASTM C1260 and room temperature over water. Figure 15 shows expansion data for the first 40 days of exposure. We observed that the expansion for the sample exposed to $100 \% \mathrm{RH}$ is about half that for the samples in $\mathrm{NaOH}$, as was expected. What is more surprising is that the lowest $w / c$ ratio gave the highest expansions. This could imply that the HPM is susceptible to ASR, even under the milder exposure conditions. It should be remembered, of course, that reactive aggregates and high alkali cement were used. From these data, it might be expected that HPC would be susceptible to ASR if alkali-susceptible aggregates were used.
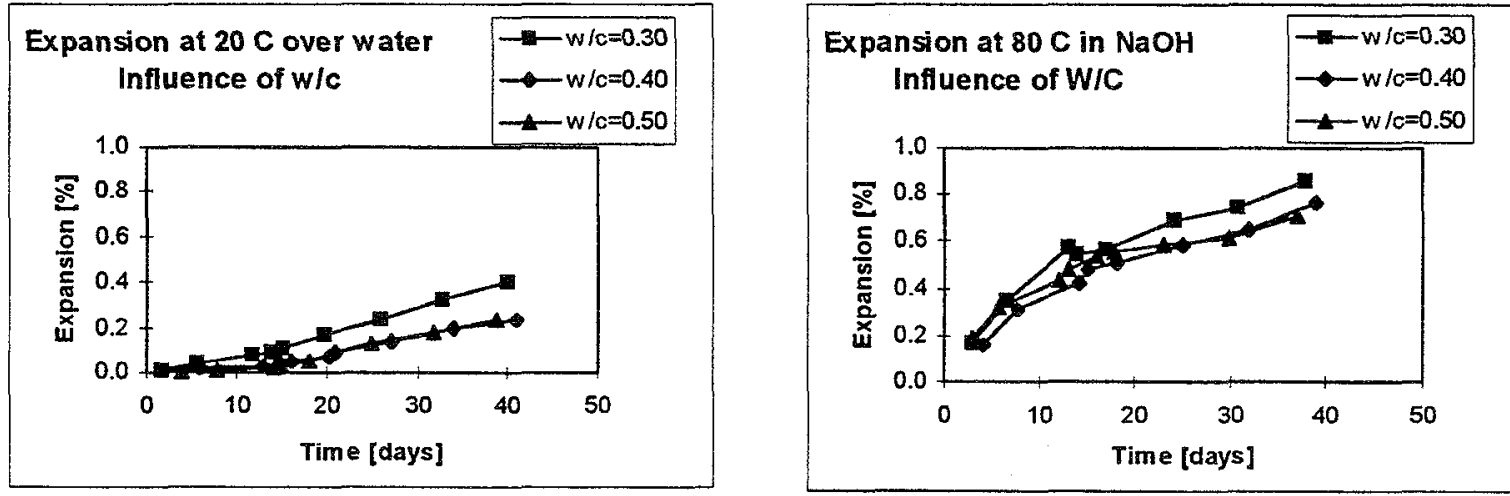

Figure 15: Expansion of HPM bars under different exposure conditions

\section{Conclusions}

The following conclusions can be drawn from this report:

- The existing rapid test ASTM C1260 cannot be applied for HPC without modification, because the mixture design is pre-determined. This test was designed to detect deleterious aggregates and the expansion with different mixture design, i.e., w/c, s/c, sand gradation.

- HPM is likely to be susceptible to ASR expansion if deleterious aggregates are used.

- There seems to be a dependance on air content such that maximum expansion was observed at $6-7 \%$ air.

- There is a trend suggesting that a longer curing increases expansion.

- The other variables tested, -- w/c, s/c, sand gradation and compressive strength -- did not seem to control the expansion due to ASR significantly. But, it should be remembered that air content is modified by changes in $w / c, s / c$ and sand gradation.

Further studies should include a wider range of variables to significantly modify the permeability of the mortar, and to include mixture designs that are currently used for concretes. The design of a test specifically adapted to HPC should be the first priority. Other characteristics of HPC, such as tensile strength, should be investigated. 


\section{Acknowledgments}

This work was sponsored by the "High Performance Construction Materials" program at NIST. I would like to thank Dr. James Clifton for the invaluable help obtained through discussions and comments on this work. John Winpigler is also acknowledged for performing the measurements. Support for this work was also obtained from the Nuclear Regulatory Commission (NRC).

\section{References}

1. Stanton T. E., "Expansion of Concrete Through Reaction Between Cement and Aggregate" Proc. of the American Soc. of Civil Eng. Vol. 66, \#10, 1940, p. 1781-1811. 2. Frohnsdorff G., Clifton J., Brown P., "History and Status of Standards Relating to Alkalies in Hydraulic Cements" Special Technical Publication \# 663, ASTM 1979, p 1634

3. Hobbs D.W., Alkali-Silica Reaction in Concrete, Thomas Telford, London 1988

4. Diamond S., Penko M., "Alkali Silica Reaction Processes: The Conversion of Cement Alkalis to Alkali Hydroxide" ,G. M. Idorn Inter. Symposium, Durability of Concrete ACI SP-131, 1992

5. Helmuth R., "Alkali-Silica Reactivity: An Overview of Research" SHRP Report C-342, 1993.

6. Capra Bruno, Bournazel Jean-Pierre, "Perspective nouvelles pour la prise en compte des alcali-reactions dans le calcul des structures" Materials and Structures, vol. 28, p. 7173,1995

7. Mindess S., "Materials selection, proportioning and quality control", High Performance Concrete: Properties and Applications, Ed. by Shah S.P., Ahmad S.H. McGraw-Hill, 1994 , p. $1-26$

8. SHRP-C/FR-91-103, High Performance Concretes, a state of the art report, Strategic Highway Research Program, National Research Council, Washington DC., 1991

9. Shah S., Ahmad S., High Performance Concrete: Properties and Applications, McGraw-Hill, 1994

10. Diamond S., "Alkali Reactions in Concrete Pore Solutions Effects", Proc. 6th Int. Conf., Alkalis in Concrete, Idorn G.M. and Rostam S. eds. 1983, p. 155-166

11. Figg J., "An Attempt to Provide an Explanation for Engineers of the Expansive Reaction between Alkalis and Siliceous Aggregates in Concrete", 6th Int. Conf. Alkalis in Concrete Copenhagen 1983.

12. Helmuth R., Stark D. "Alkali-Silica Reactivity Mechanisms", in Materials Science of Concrete III, J. Skalny ed., ACS 1992

13. Stark D., "Alkali-Silica Reactions in Concrete", in Significance of Tests and Properties of Concrete and Concrete Making Materials, Klieger P. and Lamond J. eds., ASTM STP 169C, 1994

14. Idorn G.M., Johansen V., Thaulow N., "Assessment of Causes of Cracking in Concrete", Materials Science in Concrete III, Amer. Ceramic Soc., New York, 1992 
15. Leslie Struble, The Influence of Cement Pore Solution on Alkali-silica Reaction NISTIR 87-3632, 1987

16. Baronio, Barra, Montanaro, Delmastro, Bachiorrini, "Couplage d'action de certains parametres physiques sur le developpement de la reaction alcalis-granulats", in From Material Science to Construction Materials Engineering, 1st Int. Conf. Versailles Vol. 3, 1987

17. Stark D., "Effects of Water-Cement Ratio on Expansion Due to ASR", Concrete Technology Today 1995 , p.3-5

18. Schumann David C., Carrasquillo Ramon L. and Farbiarz Josef, State-of-the-art report on the Mechanism of Alkali-Aggregate Reaction in Concrete containing Fly Ash, Research report 450-2, Center for Transportation Research 1988.

19. Carrasquillo R.L. Farbiaz J., "Alkali-Aggregate Reaction in Concrete Containing Fly Ash: Final Report" Center of Transportation Research, Research Report \#450-3F, 1988 20. Duchesne J. Berube M.A., "The Effectiveness of Supplementary Cementing Materials in Suppressing Expansion due to ASR: Another Look at the Reaction Mechanisms Part 2: Pore Solution Chemistry" Cem. and Concr. res. Vol. 24 No 2, 1994, p 221-230 21. Mindess S., "Materials selection, proportioning and quality control", High Performance Concrete: Properties and Applications, Ed. by Shah S.P. , Ahmad S.H. McGraw-Hill, 1994, p. 1-26

22. SHRP-C/FR-91-103, High Performance Concretes, a state of the art report, Strategic Highway Research Program, National Research Council, Washington DC., 1991

23. Criaud A., Cadoret G., "HPCs and Alkali Silica Reactions. The double role of pozzolanic materials" in High Performance Concrete: from Materials to Structure ,Y. Malier ed., 1992

24. Standard Test Method for Potential Alkali Reactivity of Aggregates (Mortar-Bar Method), ASTM designation C1260-94, 1994 Annual Book of ASTM Standards Vol. 04.02

25. Standard Test Method for Potential Alkali Reactivity of Cement-Aggregate Combinations (Mortar-Bar Method), ASTM designation C227-90, 1994 Annual Book of ASTM Standards Vol. 04.02

26. Criaud A., Vernet C. Defosse C. "The Microbar Method, an Accelerated Expansion Test for Evaluating Aggregates, Assessment of Canadian Aggregates", Workshop Canadian developments in Testing Alkali-Aggregate reactivity Toronto 1990.

27. Standard Test Method for Effectiveness of Mineral Admixtures of Ground BlastFurnace Slag in Preventing Excessive Expansion of Concrete Due to the Alkali-Silica Reaction, ASTM designation C 441-89,1994 Annual Book of ASTM Standards Vol. 04.02

28. Carino N. J., Knab L., Clifton J., Applicability of the Maturity Method to HighPerformance Concrete, NIST-IR \#4819, 1992

29. Fuller W.B. "The laws of Proportioning Concrete", Amer. Soc. of Civil Eng.

Transactions Vol. 59,1907 , p. $67-143$

30. Standard Specification for Flow Table for Use in Tests of Hydraulic Cement, ASTM designation C 230-90,1994 Annual Book of ASTM Standards Vol. 04.01 